\title{
Interplay of TGF $\beta$ signaling and microRNA in thyroid cell loss of differentiation and cancer progression
}

${ }^{1}$ Departamento de Biologia Celular e do Desenvolvimento, Instituto de Ciências Biomédicas, Universidade de São Paulo, São Paulo, SP, Brasil

\author{
Correspondence to: \\ Edna T. Kimura \\ Instituto de Ciências Biomédicas \\ Universidade de São Paulo \\ Av. Professor Lineu Prestes, 1524 \\ sala 414, Butantã \\ 05508-000 - São Paulo, SP, Brazil \\ etkimura@usp.br \\ Received on May/6/2019 \\ Accepted on Aug/4/2019 \\ DOI: 10.20945/2359-39970000000172
}

\section{Cesar Seigi Fuziwara ${ }^{1}$ \\ https://orcid.org/0000-0002-0567-5432 \\ Kelly Cristina Saito ${ }^{1}$ \\ https://orcid.org/0000-0001-6397-6754}

Edna Teruko Kimura'

https://orcid.org/0000-0001-8403-4459

\begin{abstract}
Thyroid cancer has been rapidly increasing in prevalence among humans in last 2 decades and is the most prevalent endocrine malignancy. Overall, thyroid-cancer patients have good rates of long-term survival, but a small percentage present poor outcome. Thyroid cancer aggressiveness is essentially related with thyroid follicular cell loss of differentiation and metastasis. The discovery of oncogenes that drive thyroid cancer (such as RET, RAS, and BRAF), and are aligned in the MAPK/ERK pathway has led to a new perspective of thyroid oncogenesis. The uncovering of additional oncogenemodulated signaling pathways revealed an intricate and active signaling cross-talk. Among these, microRNAs, which are a class of small, noncoding RNAs, expanded this cross-talk by modulating several components of the oncogenic network - thus establishing a new layer of regulation. In this context, TGF $\beta$ signaling plays an important role in cancer as a dual factor: it can exert an antimitogenic effect in normal thyroid follicular cells, and promote epithelial-to-mesenchymal transition (EMT), cell migration, and invasion in cancer cells. In this review, we explore how microRNAs influence the loss of thyroid differentiation and the increase in aggressiveness of thyroid cancers by regulating the dual function of TGF $\beta$. This review provides directions for future research to encourage the development of new strategies and molecular approaches that can improve the treatment of aggressive thyroid cancer. Arch Endocrinol Metab. 2019;63(5):536-44
\end{abstract}

Keywords

Thyroid cancer; microRNA; TGF $\beta$; EMT; thyroid cell differentiation

\section{THYROID CANCER}

$\mathrm{T}$ hyroid cancer is the most common malignancy of the endocrine system, and its global incidence has increased in recent years; 52070 new cases are expected to occur in the United States in $2019(1,2)$. The majority of thyroid cancers originate from the follicular cells; in terms of histological and clinical behavior, these cancers are classified as well-differentiated, poorly differentiated and undifferentiated (3). Among differentiated thyroid cancers, papillary thyroid cancer (PTC) comprises more than $80 \%$ of cases; the remainder consists of follicular thyroid cancer. Although less frequent (2\%-5\% of cases), the undifferentiated thyroid cancer or anaplastic thyroid cancer (ATC) is the most aggressive and lethal type of thyroid cancer $(3,4)$.

The main oncogenic alterations of thyroid cancer occur in genes that are aligned with the MAPK pathway. BRAF and RAS mutations, and RET/ PTC rearrangements can impair the differentiation of the thyroid follicular cells and lead to PTC oncogenesis due to the constitutive activation of MAPK/ERK signaling $(4,5)$. The acquisition of additional molecular alterations in coding genes (e.g., PIK3CA and AKTI) may also contribute to loss of differentiation, refractoriness to radioiodine therapy, and aggressive behavior (6). Additionally, the oncogenic activation of the MAPK pathway triggers the deregulation of microRNAs (miRNAs), which comprise a class of small noncoding RNAs that exert a potent inhibitory effect on protein expression at the posttranscriptional level. Because miRNAs modulate targets in several oncogenic pathways (7), they expand the network of oncogene-modulated genes in thyroid cells' functioning and biology. 


\section{MICRORNA AND THYROID FOLLICULAR CELL DIFFERENTIATION}

Thyroid-gland epithelial cells (known as thyrocytes or thyroid follicular cells) are organized in follicles; the previously synthesized thyroid hormones are confined to the follicular lumen. These cells have the unique ability to incorporate the iodine molecule as a thyroid hormone compound (8). The thyrocytes' differentiated status (i.e., the ability to trap iodine and produce thyroid hormones) is associated with the expression of genes related to iodine metabolism such as NIS (sodium iodide symporter), TPO (thyroperoxidase), TG (thyroglobulin), and DUOX (dual oxidase); all of these are directly involved in trapping iodine and metabolizing it into the thyroid hormones. These genes are under the regulation of thyroid transcription factors (TFs) such as NKX2-1 (NK2 homeobox 1, previously known as TTFl), FOXEl (forkhead box El, also known as TTF2), and PAX8 (paired box 8), which are uniquely co-expressed in the thyroid gland (9).

Moreover, thyrocytes' function is regulated by the pituitary thyroid-stimulating hormone via its receptor $(T S H R)$, which is expressed in the basolateral membrane of thyroid follicular cells. TSH signaling activation induces thyroid cell differentiation by directly stimulating the expression of genes such as NIS, TPO, and $T G$ through the binding of cAMP to its responsive element in the promoter region of these genes (10).

Since the discovery of miRNA moleculesin 1993, more than 2000 human miRNA genes have been described in human genome (miRBase, release 22.1) (11). Mature miRNAs consist of small, noncoding RNAs with $~ 22 \mathrm{nt}$ that posttranscriptionally control gene expression by binding to the 3' untranslated region within the target mRNAs $(12,13)$. The overall effect of miRNA binding is a reduction in protein levels due to impairment of the ribosome assembly or the induction of mRNA decay (13). Overexpression of miRNA represses the expression of target mRNA, and conversely, the loss of miRNA expression enhances the expression of mRNA. Thus, unbalanced miRNA expression is involved in the pathogenesis of human diseases, including cancer, for which unbalanced miRNA acts in an oncogenic or tumor-suppressive fashion. In terms of bioinformatics, miRNAs regulate more than $60 \%$ of protein-coding genes' mRNAs (based on miRNA seed-sequence conservation) (12); this indicates that these noncoding
RNAs could regulate all cellular processes, including thyroid-cell differentiation and tumorigenesis $(7,15)$.

Normally, the thyroid gland expresses a specific constitutive pool of miRNAs that includes let-7 isoforms (let-7a, let-7b, let-7c, let-7d, let-7e, let-7g, and let-7i), miR-15/miR-16 cluster, miR-30a/miR-30c/ $m i R-30 d, m i R-125 b, m i R-200 c, m i R-99 b$, and $m i R-$ 138 (16). Strikingly, several of these thyroid-specific miRNAs are deregulated in thyroid cancer, which indicates that oncogenic activation could interfere with thyroid cells' function by changing the levels of the miRNAs (Figure 1). However, some miRNAs that are not expressed in normal thyroid cells are activated in thyroid cancer. One of the hallmarks of miRNAs in PTC is $m i R-146 b$, consistently increased in PTC, and which expression correlates with a poor prognosis $(5,17)$.

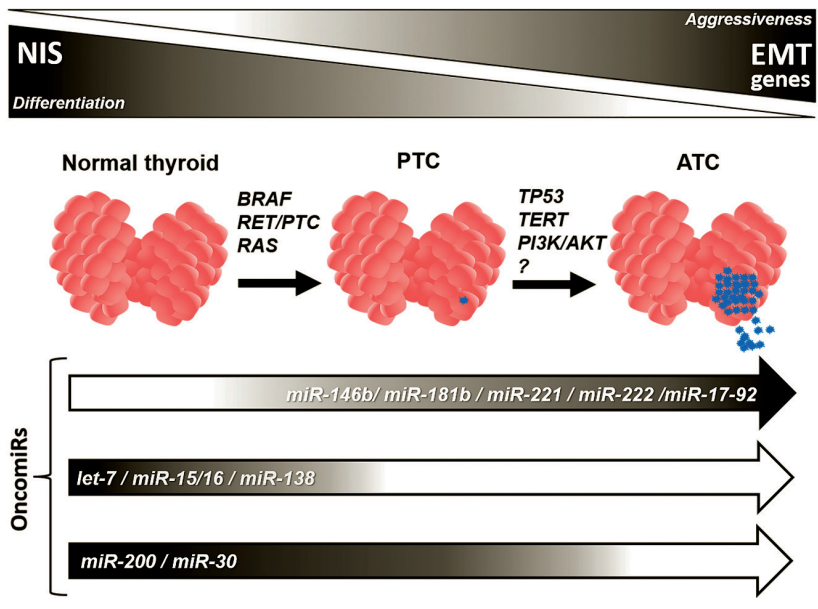

Figure 1. Oncogene activation induces thyroid cancer and leads to deregulation of miRNA expression (loss or gain of expression). The loss of NIS expression is key for the thyroid dedifferentiation and impairment of responsiveness to radioiodine therapy. The activation of epithelial-tomesenchymal transition (EMT) genes expression contributes to cancer progression and aggressive phenotype. Modified from Fuziwara \& Kimura (14).

The results of a Dicerl knockdown study highlight the importance of miRNAs for thyroid cells' differentiation (18). Primary miRNA is transcribed and, sequential cleavage processes that occur in the nucleus and cytoplasm generate mature miRNA. The main protein involved in the final step of miRNA biogenesis is the ribonuclease DICER (19). Indeed, Dicer 1 knockdown resulted in severe downregulation of thyroid cell-differentiation genes Nis, Tpo, Tg, Nkx2-1 and Pax 8 in normal rat thyroid follicular cell line $\mathrm{PCCl} 3$ in vitro (18). Additionally, across three studies of Dicer 1 transgenic knockout mice, a similar effect occurred in the thyroid gland, with decreased expression of 
thyroid-differentiation markers, severe impairment of thyroid-hormone secretion and hypothyroidism, and interestingly - loss of thyroid histological organization $(20,21)$. This global downregulation of miRNAs caused by the Dicerl knockout indicates that the miRNAs' regulatory network also controls the thyroid gland's functioning. Indeed, the results of an in silico analysis (using a bioinformatics algorithm for target prediction) reveal that several miRNAs could target thyroid-differentiation genes and TFs (15).

Interestingly, thyroid TF PAX8 can drive the expression of $m i R-146 b$ by binding to $m i R-146 b$ promoter; similarly, the TF NKX2-1 does so by binding to $m i R-532-5 p$ promoter $(22,23)$; this indicates the existence of an intricate regulatory network between thyroid TFs and miRNAs for the control of thyroid follicular cells' function. Moreover, to date, a few miRNAs are directly associated with the regulation of thyroid differentiation genes. Among them, the 3' strand of miR-146b (miR-146b-3p) targets NIS mRNA in NISexpressing cells and thus reduces radioiodine uptake (23). Similarly, an in silico analysis led to the discovery of $m i R$ $339-5 p$ as a novel regulator of NIS expression, impacting thyroid follicular cells' function (24).

In addition, miRNA could also regulate thyroid differentiation in an indirect manner. For example, $m i R-106 a$ is upregulated in the serum of patients who have thyroid-cancer metastases in the lung that are not avid for radioiodine (25). Similarly, miR-106a regulates the expression of retinoic acid receptor beta, $(R A R \beta)$ which influences thyroid cells' differentiation. The overexpression of miR-106a in the PTC cell line increases cell viability and invasion but reduces apoptosis; the opposite occurs when inhibiting $m i R$ $106 a$ in ATC cell lines. Moreover, targeting miR$106 a$ with antagomir increases the expression of NIS and TSHR while sensitizing ATC cells to radioiodine treatment (25). Interestingly, $m i R-146 b$ regulates the expression of RAR $\beta$ (26) and serum $m i R-146 b$ levels are also associated with thyroid tumors poor prognosis (27).

\section{TGF $\beta$ SIGNALING AND THYROID FUNCTION}

Transforming Growth Factor $\beta$ (TGF $\beta$ ) signaling is an important pathway in thyroid cells' function and homeostasis. Classically, TGF $\beta$ signaling is a tumor suppressor in normal epithelial cells (e.g., thyrocytes), as it exerts an antimitogenic effect; nevertheless, the cumulative evidence shows that it plays additional roles in thyroid-cell differentiation and in the epithelial-tomesenchymal transition (EMT) process, and promotes malignant progression of cancer.

The cascade of TGF $\beta$ signaling activation initiates when the TGF $\beta$ isoforms (TGF $\beta 1$, TGF $\beta 2$, and TGF $\beta 3$ ) are bound to the membrane-receptor serine kinases of the TGF $\beta$ family. Ligand binding forms a heterodimeric complex that comprises two type-II (TGFBR2) and two type-I (TGFBRI) receptors. Then, TGFBR2 phosphorylates TGFBRI for at multiple serine threonine residues in the $\mathrm{N}$-terminal region. Activated TGFBRI recruits and phosphorylates SMAD2 and SMAD3 proteins (R-SMADs), leading to the formation of the SMAD2/3 and SMAD4 heterotrimeric complex. Subsequently, this complex translocates to the nucleus and binds to the SMAD-binding element of the DNA in order to modulate the transcription of target genes such as cell-cycle inhibitors (e.g., p2 $1^{\mathrm{CIPl}}$ and pl $\left.5^{\mathrm{INK} 4}\right)$. SMAD7, a negative regulator of this pathway, interacts with activated receptors and R-SMADs, thus suppressing translocation. Moreover, SMURFl/2 exerts posttranslational regulation by ubiquitination of SMAD proteins and receptors, leading to ubiquitinproteasome degradation (28).

Thyroid tumors express TGF $\beta / S M A D$ signaling components $(29,30)$, unlike other types of cancer (which typically harbor genetic alterations in this pathway). Instead, signaling transduction deregulation is related to the modulation of its components through oncogene-induced posttranscriptional changes, as well as through posttranslational modifications such as ubiquitination, or through the signaling transduction inhibition by SMAD7. Indeed, low levels of SMAD4 can occur in PTC cell lines, thus causing refractoriness to TGF $\beta$ 's cytostatic effect (29). Acute BRAF ${ }^{\mathrm{V} 600 \mathrm{E}}$ activation in normal thyroid follicular cells leads to both downregulation of SMAD4 and refractoriness to TGF $\beta 1$-induced cell-cycle arrest via the activation of the miR-17-92 cluster and miR-146b. Moreover, the blockage of these miRNAs using antisense oligonucleotides with locked nucleic-acid (LNA) modifications (antagomirs) results in the recovery of SMAD4 protein levels and increased responsiveness to TGF $\beta 1$ 's antimitogenic effect $(31,32)$.

In addition to the classical antiproliferative effect of the TGF $\beta /$ SMAD pathway (activation of cell-cycle arrest), TGF $\beta$ is a well-known inhibitor of thyroid differentiation and growth $(33,34)$. The treatment of FRTL5 cells (a normal rat thyroid follicular cell line) 
with exogenous TGF $\beta 1$ leads to downregulation of Nis, Tpo and Tg. Moreover, the disruption of TGF $\beta$ signaling transduction (in this case, using a SMAD4 dominant negative protein in FRTL5 cells) also results in the loss of differentiation - to a similar extent as for TGF $\beta$-treated cells (35) The molecular basis for this regulation is attributed to the binding of SMAD3 to PAX8, which in turn impairs PAX8's action on the Nis upstream enhancer and leads to Nis transcriptional repression (36). Indeed, TGF $\beta$ impairs $\mathrm{Tg}$ transcription by reducing the levels of PAX8, thus diminishing its DNA-binding activity (37). Interestingly, in normal thyroid cells in vitro, $\mathrm{BRAF}^{\mathrm{V} 600 \mathrm{E}}$ activation also represses NIS expression via the increased secretion of TGF $\beta$ (38). Additionally, TGF $\beta$ signaling can regulate the expression of NKX2-1 via a miRNA loop, wherein TGF $\beta$ treatment induces miR-365 which targets NKX2-1, while miR-365 overexpression induces TGF $\beta$ secretion (39).

The high expression of TGF $\beta 1$ occurs in the invasive fronts of PTC, correlating with the loss of thyroid differentiation (38); and it is also observed in poorly circumscribed PTC that shows high levels of TGF $\beta$ in the tumor-periphery invasive front; on the other hand, in well-circumscribed PTC, the center of the (noninvasive) tumor shows inhibition of TGF $\beta$ signaling (high SMAD7 levels) (40).

\section{TGF $\beta$ AND MIRNAS IN EMT REGULATION}

TGF $\beta$ signaling plays a dual role, and its function depends on the cellular context. Although, in normal epithelial cells, its signaling induces the expression of the p21 and p27 cell-cycle inhibitors to block cell proliferation, in cancer cells, TGF $\beta$ promotes EMT, which is a hallmark for cancer progression (41). In a recent study, Xu and cols. (42) shed some light into the molecular mechanism that breast-cancer cells use to reprogram the TGF $\beta$ antiproliferative signaling and to promote EMT and metastasis; the results indicate that YWHAZ (14-3-35) activation is key to overcoming the cytostatic effect of TGF $\beta$ because it blocks the p53/SMAD association and induces GLI2/ SMAD interaction in breast cancer bone metastasis.

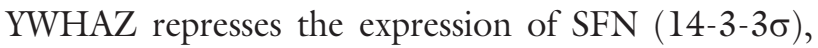
which is necessary to stabilize p53 protein levels, and consequently leads to a loss of TGF $\beta$-induced p21 expression (42).

EMT is a general term that is used to describe the mechanism through which a polarized cell undergoes a series of molecular changes to acquire a mesenchymal phenotype, which enhances the migratory and invasive potential and improves the extracellular matrix's secretory ability (43). EMT can be further classified into 3 types: type I, which occurs during embryo implantation and gastrulation; type 2, which is activated by injury or inflammation in normal tissues; and type 3, which is activated during cancer progression (43).

EMT is classically activated by TGF $\beta$-signaling transduction via SMAD proteins; this leads to transcriptional changes that downregulate epithelial genes (E-cadherin, cell-to-cell junctions, and cellpolarity genes), that induce mesenchymal genes (N-cadherin and extracellular-matrix interaction genes), and that lead to cytoskeleton remodeling (44). This process depends on the activation of three families of EMT TFs: SNAIL, ZEB, and bHLH (which includes Twist). ZEB1, ZEB2, SNAIl, SNAI2 (SLUG), and TWISTl are the master EMT TFs as they autoregulate each other and cooperatively repress the transcription of E-cadherin ( $\mathrm{CDHl}$ gene), which is the hallmark of EMT - all while orchestrating changes to the expression profile that lead to the EMT phenotype shift (4l).

In a zebrafish model model, $\mathrm{BRAF}^{\mathrm{V} 600 \mathrm{E}}$-induced PTC led to EMT activation and thyroid-gland disorganization via the TF TWIST2 (45). Moreover, $\mathrm{BRAF}^{\mathrm{V} 600 \mathrm{E}}$ activation in the thyroid gland of transgenic mice (Tg-Braf) generated PTC with regions of poorly differentiated thyroid cancer at the late stage (5 months) (46). A microarray gene-expression profile comparison of PTC and poorly differentiated tumors in transgenic Tg-BRAF mice revealed a reduction of cell-adhesion genes such as E-cadherin and an increase in the intermediate filament vimentin. Indeed, the TGF $\beta$-signaling pathway was activated in these poorly differentiated tumors, which show high levels of pSMAD2, repression of E-cadherin, and upregulation of the vimentin protein (46). Interestingly, TGF $\beta$-signaling activation is dependent on MAPK signaling, as a treatment with U0126 (a MEK inhibitor) blunts SMAD2 phosphorylation and blocks TGF $\beta$ induced genes in BRAF-induced, PTC-derived primary cells (46).

Furthermore, the signaling activation of MAPKusing $\mathrm{BRAF}^{\mathrm{V} 600 \mathrm{E}}$ induces the ETV5 TF, which subsequently modulates TWISTl expression transcriptionally to promote EMT in thyroid-cancer cells (47). Conversely, in a human PTC cell line, ETV5 knockdown attenuated this phenotype and reduced cell migration, invasion, 
and proliferation. Moreover, high nuclear levels of TWISTl in PTC cell lines are positively correlated with metastasis and are associated with the $\mathrm{NF \kappa B}$-signaling pathway activation as the knockdown of NFkB blocks TWISTl upregulation (48).

There is an intricate network of regulation between miRNA and TGF $\beta$ signaling. On the one hand, miRNAs can target the TGF $\beta$ pathway's components, thus acting as oncomiRs (miRNAs that are deregulated during oncogenesis and cancer progression), as shown in Table 1 . On the other hand, TGF $\beta$ signaling can modulate miRNA expression through two mechanisms: (a) influencing the transcriptional activity of miRNA genes by binding the PSMAD complex to the promoter region of these genes at the sites of the SMAD-binding element or (b) modulating the processing of precursor miRNA (pre-miRNA) into mature miRNA. For example, the binding of SMAD2 $/ 3$ to a SMAD-binding element's region in the primary miRNA stabilizes the microprocessor complex (DROSHA, DGCR8, and p68) and induces the maturation of pre-mir-21 and pre-mir-199a in the vascular smooth muscle (49).

The discovery of miRNA networks has shed light on EMT, as these networks can regulate several features of the EMT signaling transduction, from the proteins that act as activators (such as TGF $\beta$ and its pathway) to the EMT TFs (Figure 2). The results of a seminal study show that activation of the protein tyrosine phosphatase Pez in combination with TGF $\beta$ signaling significantly silences both the $m i R-200$ superfamily and $m i R-205$ (50) At the same time, when different human cancer cell lines are stratified according to the levels of epithelial (high in E-cadherin) and mesenchymal (high in vimentin) gene signatures, the miRNA signature of the mesenchymal-phenotype cancers show strong downregulation of the miR-200 family (51). In humans, the miR-200 family is composed of 5 miRNAs that share 2 seed regions $(m i R-200 a / 141$ and $m i R-200 b / c / 429)$ across independent clusters: chrl2 (miR-200c/14l) and chrl (miR-200a/b/429) (50).

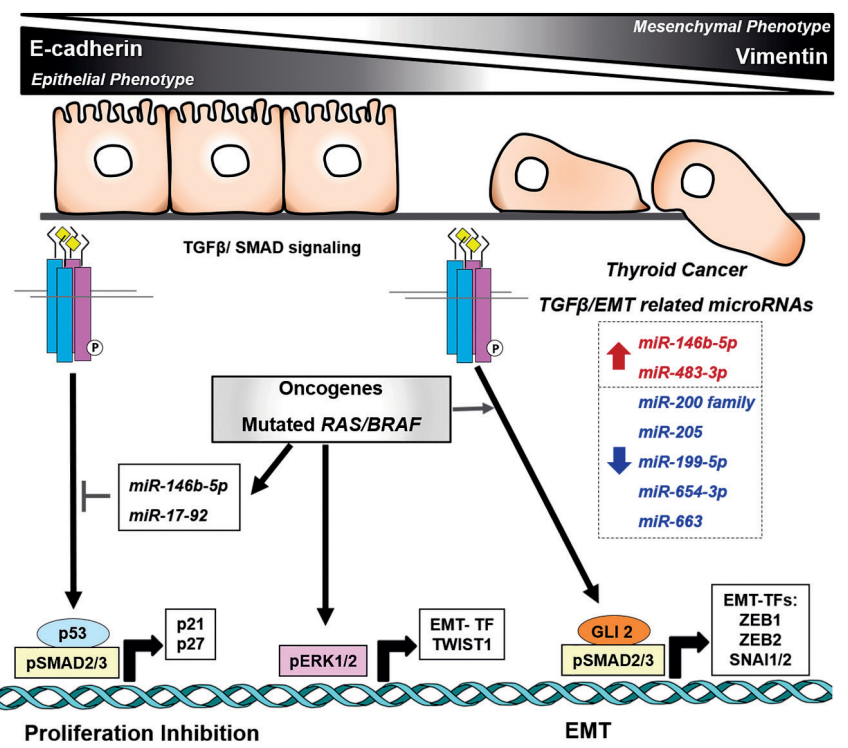

Figure 2. TGF $\beta$ signaling exerts a dual role in thyroid follicular cells. In normal cells, TGF $\beta$ induces antimitogenic effect by induction of p21/p27, while upon activation of MAPK oncogenes and cell transformation, TGF $\beta$ promotes EMT and invasion via induction of EMT transcription factors (EMT-TFS). At the right side, the list of deregulated miRNAs that contribute to TGF $\beta$-induced EMT in aggressive thyroid cancer, leading to loss of epithelial phenotype (E-cadherin) and acquisition of mesenchymal phenotype (Vimentin).

Table 1. Bioinformatic prediction of microRNAs that target mRNA related with TGF $\beta$ signaling pathway

\begin{tabular}{|c|c|c|c|c|c|c|c|}
\hline mRNA & & & & microRNAs ${ }^{\star}$ & & & \\
\hline TGFBR1 & $m i R-181-5 p$ & $\operatorname{miR}-133 a-3 p$ & $m i R-142-3 p$ & Let-7 & $\operatorname{miR}-183-5 p$ & $m i R-101-3 p$ & mir-208-3p \\
\hline TGFBR2 & $m i R-17 / 20-5 p$ & $m i R-19-3 p$ & $m i R-21-5 p$ & $m i R-302-3 p$ & $m i R-130-3 p$ & $m i R-142-5 p$ & $\operatorname{miR}-144-3 p$ \\
\hline SMAD2 & $m i R-18 a-5 p$ & Let-7-5p & $m i R-200 b / c / 429$ & $m i R-142-5 p$ & $m i R-128-3 p$ & $\operatorname{miR}-155-5 p$ & $m i R-181-5 p$ \\
\hline SMAD3 & $\operatorname{miR}-145-5 p$ & $\operatorname{miR}-15 / 16$ & $\operatorname{miR}-129-3 p$ & $m i R-23-3 p$ & $m i R-216-5 p$ & $m i R-143-3 p$ & $m i R-18-5 p$ \\
\hline SMAD4 & $m i R-146 b-5 p$ & $\operatorname{miR}-17$ & $\operatorname{miR}-19$ & $\operatorname{miR}-18 a$ & $\operatorname{miR}-142-3 p$ & miR-34 & $\operatorname{miR}-205-5 p$ \\
\hline SMAD7 & miR-21 & $m i R-181-5 p$ & $\operatorname{miR}-182-5 p$ & $m i R-17 / 20$ & $\operatorname{miR}-15 / 16$ & $m i R-200 b / c$ & miR-25 \\
\hline SMURF1 & $m i R-19-3 p$ & $\operatorname{miR}-15 / 16$ & $\operatorname{miR}-137$ & $\operatorname{miR}-25-3 p$ & $\operatorname{miR}-142-5 p$ & $m i R-200 b c$ & $\operatorname{miR}-153-3 p$ \\
\hline SMURF2 & $m i R-19-3 p$ & $\operatorname{miR}-15 / 16$ & $\operatorname{miR}-137$ & miR-124-3p & $m i R-142-3 p$ & $m i R-200 b c$ & $m i R-130-3 p$ \\
\hline ARKADIA (RNF111) & $\operatorname{miR}-19-3 p$ & $\operatorname{miR}-15 / 16$ & $m i R-21-5 p$ & $\operatorname{miR}-142-3 p$ & $\operatorname{miR}-144-3 p$ & $\operatorname{miR}-155-5 p$ & $\operatorname{miR}-9-5 p$ \\
\hline
\end{tabular}

* Prediction based on TargetScanHuman Release 7.2 (http://www.targetscan.org/vert_72/). 
The functional investigation of $m i R-200 s$ shows that, on the one hand, miR-200 expression blocks EMT by targeting the ZEBl/ZEB2 TFs that downregulate E-cadherin, but that, on the other hand, ZEBI transcriptionally inhibits $m i R-200$ expression in a negative feedback loop $(50,51)$. Indeed, the $m i R$ 200 family is downregulated in anaplastic thyroid carcinoma (52). The results of a microarray geneexpression analysis reveal that the $m i R-200 c / 141$ and $m i R-200 b / a / 429$ clusters are severely repressed in ATC cells, as compared to normal thyroid cells and cells from other types of thyroid cancer such as PTC and follicular thyroid cancer (52). Interestingly, $m i R-200 c$ expression (together with the let-7 family) is among the 10 most abundant miRNAs in normal thyroid glands (16), which indicates that the miR-200 family plays an important role in thyroid biology. In normal thyroid cells, the activation of the Epidermal Growth Factor (EGF) signaling pathway inhibits the miR-200 family and induces EMT, with a loss of E-cadherin. On the other hand, in the anaplastic thyroid carcinoma cell line and in xenotransplant tumors, blockage of EGFR signaling restores $m i R-200$ expression and also induces both the mesenchymal-to-epithelial transition and E-cadherin upregulation (53). Similarly, miR-205 downregulation is associated with TGF $\beta$-induced EMT and cooperates with $m i R-200$ family (50). In anaplastic thyroid cancer, miR-205 overexpression blocks EMT and cell invasion, and restores E-cadherin expression. Moreover, miR-205 inhibits VEGF-A secretion and angiogenesis in vitro and tumor growth mouse xenotransplant (54).

Recent data further have indicated that a new set of miRNAs regulate the thyroid-cancer EMT process (Figure 2). For instance, in PTC samples, miR-199-5p is downregulated and inversely correlated with SNAII mRNA levels. In thyroid-cancer cell lines, the restoration of $m i R-199-5 p$ levels leads to SNAII repression, which in turn leads to the inhibition of $\mathrm{N}$-cadherin and vimentin, as well as the induction of E-cadherin (55). Indeed, miR-199-5p represses SNAII by binding to the mRNA's 3' untranslated region, and SNAII knockdown reduces cell invasion and tumor growth in xenotransplants. This indicates the important role of $m i R-199-5 p$ as an EMT inhibitor. Moreover, in PTC, miR-663 is a target of TGF $\beta 1$-induced EMT and is downregulated. Ectopic expression of miR-663 in the BCPAP and IHH4 PTC cell lines causes the restoration of E-cadherin levels in a similar way as in the silencing of TGFßl (56). In addition, miR-654$3 p$ is downregulated in human PTC samples and in thyroid-cancer cell lines. BRAF ${ }^{\mathrm{V} 600 \mathrm{E}}$ oncogene-induced mouse PTC suppresses miR-654-3p levels in the late stage, inversely correlating with increases in the EMT TFs Zeb1, Zeb2, Snail e Snai2 (57). The reintroduction of $m i R-654-3 p$ in thyroid-cancer cells reduces cell migration and decreases Snai2 transcription, while also increasing E-cadherin levels.

Additionally, miRNA upregulation can promote thyroid cancer EMT. The results of a recent study show that $m i R-483-3 p$ plays a role in regulating the PARD3 polarity gene in ATC, thus enhancing the EMT process (58). Indeed, $m i R-483-3 p$ is highly expressed in ATC cell lines, and it can be induced via TGF $\beta$ treatment to target PARD3 mRNA. The loss of PARD3 occurs in thyroid cancer (as compared to a nontumoral counterpart); and low levels of PARD3 are inversely correlated with $m i R-483-3 p$ expression. Blocking $m i R-483-3 p$ using antagomirs inhibits TGF $\beta$-induced cell invasion and prevents PARD3 downregulation. Interestingly, PARD3 rescue in ATC cells leads to the blockage of TGF $\beta$-induced effects via the maintenance of E-cadherin levels and the inhibition of vimentin (58).

Hardin and cols. reported an additional loop of TGF $\beta$-miRNA interaction, showing upregulation of miR 146-5b expression in PTC cell line exposed to TGF $\beta 1$ (59). Moreover, the treatment of PTC cells with TGF $\beta 1$, both in vitro and in a xenograft model, downregulates E-cadherin and induces SLUG, SNAI, TWIST, and vimentin (59). Indeed, miR 146-5p is one of the most highly expressed miRNAs in BRAFmutated PTC $(5,17)$ and it targets zinc and ring finger 3 (ZNRF3), which is a modulator of Wnt/ $\beta$-catenin signaling. In PTC, the high expression of miR 146-5p suppresses ZNRF3 and enhances the expression of EMT markers (60).

Interestingly, distant metastases that arise from carcinomas usually show a well-differentiated epithelial phenotype; this hints at another interesting aspect of EMT: its reversibility in the mesenchymal-to-epithelial transition. In a seminal study, Ocana and cols. (61) found that TGF $\beta$-induced EMT involves the activation of the TF paired-related homeobox-1 (PRRXI), which is expressed in the normal development of somites' mesenchymal cells. PRRXI overexpression is sufficient to induce EMT in MDCK cells; this leads to the mesenchymal phenotype, including invasion, loss of E-cadherin, expression of vimentin, and activation 
of some EMT TFs (61). However, according to the results of a tail-vein injection assay, the cancer cells that overexpress PRRXI, although relatively invasive, cannot colonize distant sites; this shows that, the loss of PRRXI is essential for lung colonization, as it reverses the EMT via the recovery of the epithelial phenotype (61).

\section{PERSPECTIVES}

Recent therapeutic strategies have been intended to improve radioiodine uptake in advanced thyroid cancer through the use of MAPK signaling inhibitors. However, resistance to these inhibitors is somewhat common, so there is an urgent need to develop adjuvant therapies. For example, a combinatorial therapy with MAPK-signaling inhibitors and histone-deacetylase inhibitors showed a synergistic effect in reexpressing the NIS gene and in recovering the radioiodine trapping in $\mathrm{BRAF}^{\mathrm{V} 600 \mathrm{E}}$ thyroid-cancer cell lines (62). On the other hand, researchers have investigated the efficacy of the TGF $\beta$ pathway inhibition in preclinical and clinical trials using several TGF $\beta$ antagonists, including TGF $\beta$ antibodies, antisense oligonucleotides, and receptorkinase inhibitors. In cancer, this inhibition could attenuate the TGF $\beta$-dependent EMT; however, due to the pleiotropic functions of TGF $\beta$ signaling - which regulates many normal physiological functions and various steps of cancer progression - the effects of TGF $\beta$ inhibitors in cancer therapy remain unpredictable (63). Furthermore, the progressive cascade of events in cancer metastasis is activated by TGF $\beta$, which recruits several cell types in the tumor microenvironment - not just primary tumor cells but also stromal and immune cells (64). Thus, developing a strategy to target all cell types at once is a challenge in the development of any targeted molecular therapy.

The picture that emerges from this evidence is that modulating deregulated miRNAs, in combination with the conventional or new generation of inhibitors, could help to reestablish thyroid cells' iodine-trapping function. This treatment could thus act as an adjuvant therapy in iodine-refractory thyroid cancer and could influence the EMT phenotype. For example, miR-146b is upregulated in a differentiated thyroid-carcinoma-cell model in which radioiodine resistance is acquired after radioiodine exposure, leading to the downregulation of the thyroid-differentiation genes (65). Interestingly, the inhibition of $m i R-146 \mathrm{~b}$ can restore thyroid differentiation and radioiodine trapping via the upregulation of NIS levels; this inhibition thus exerts a global effect in cell biology by reducing cell viability and inducing apoptosis. Conversely, reexpression of the $m i R-200$ family, as well as of $m i R-205$ and other downregulated miRNAs, could improve thyroidcancer prognosis by blunting the EMT and metastasis processes. In this regard, the strategy of targeting miRNAs could have a potential broad effect as those miRNAs control a plethora of genes.

Acknowledgments: Research Grants and Scholarships from FAPESP: 2016/17129-4, 2014/50521-0; CNPq 458505/ 2014-5, 308331/2017-6, 151789/2018-5, 430756/2018-6; and NAPmiR-USP.

Disclosure: no potential conflict of interest relevant to this article was reported.

\section{REFERENCES}

1. Siegel RL, Miller KD, Jemal A. Cancer statistics, 2019. CA Cancer J Clin. 2019;69(1):7-34.

2. Janovsky C, Bittencourt MS, Novais MAP, Maciel RMB, Biscolla RPM, Zucchi P. Thyroid cancer burden and economic impact on the Brazilian public health system. Arch Endocrinol Metab. 2018;62(5):537-44.

3. Kondo T, Ezzat S, Asa SL. Pathogenetic mechanisms in thyroid follicular-cell neoplasia. Nat Rev Cancer. 2006;6(4):292-306.

4. Fagin JA, Wells SA Jr. Biologic and clinical perspectives on thyroid cancer. N Engl J Med. 2016;375(11):1054-67.

5. Cancer Genome Atlas Research N. Integrated genomic characterization of papillary thyroid carcinoma. Cell. 2014;159(3):676-90.

6. Schmidt A, Iglesias L, Klain M, Pitoia F, Schlumberger MJ. Radioactive iodine-refractory differentiated thyroid cancer: an uncommon but challenging situation. Arch Endocrinol Metab. 2017;61(1):81-9.

7. Pallante P, Battista S, Pierantoni GM, Fusco A. Deregulation of microRNA expression in thyroid neoplasias. Nat Rev Endocrinol. 2014;10(2):88-101.

8. Carvalho DP, Dupuy C. Thyroid hormone biosynthesis and release. Mol Cell Endocrinol. 2017;458:6-15.

9. Fernandez LP, Lopez-Marquez A, Santisteban P. Thyroid transcription factors in development, differentiation and disease. Nat Rev Endocrinol. 2015;11(1):29-42.

10. Ortiga-CarvalhoTM, Chiamolera MI, Pazos-Moura CC, Wondisford FE. Hypothalamus-pituitary-thyroid axis. Compr Physiol. 2016;6(3):1387-428.

11. Kozomara A, Griffiths-Jones S. miRBase: annotating high confidence microRNAs using deep sequencing data. Nucleic Acids Res. 2014;42(Database issue):D68-73.

12. Friedman RC, Farh KK, Burge CB, Bartel DP. Most mammalian mRNAs are conserved targets of microRNAs. Genome Res. 2009;19(1):92-105.

13. Pasquinelli AE. MicroRNAs and their targets: recognition, regulation and an emerging reciprocal relationship. Nat Rev Genet. 2012;13(4):271-82.

14. Fuziwara CS, Kimura ET. MicroRNA deregulation in anaplastic thyroid cancer biology. Int J Endocrinol. 2014;2014:743450.

15. Fuziwara CS, Kimura ET. MicroRNAs in thyroid development, function and tumorigenesis. Mol Cell Endocrinol. 2017;456:44-50. 
16. Marini $F$, Luzi E, Brandi ML. MicroRNA role in thyroid cancer development. JThyroid Res. 2011;2011:407123.

17. He H, Jazdzewski K, Li W, Liyanarachchi S, Nagy R, Volinia S, et al. The role of microRNA genes in papillary thyroid carcinoma. Proc Natl Acad Sci U S A. 2005;102(52):19075-80.

18. Penha RCC, Sepe R, De Martino M, Esposito F, Pellecchia S, Raia $\mathrm{M}$, et al. Role of Dicer1 in thyroid cell proliferation and differentiation. Cell Cycle. 2017:1-8.

19. Lin S, Gregory RI. MicroRNA biogenesis pathways in cancer. Nat Rev Cancer. 2015;15(6):321-33.

20. Frezzetti D, Reale C, Cali G, Nitsch L, Fagman H, Nilsson O, et al. The microRNA-processing enzyme Dicer is essential for thyroid function. PLoS One. 2011;6(11):e27648.

21. Rodriguez W, Jin L, Janssens $V$, Pierreux C, Hick AC, Urizar E, et al. Deletion of the RNaselll enzyme dicer in thyroid follicular cells causes hypothyroidism with signs of neoplastic alterations. PLoS One. 2012;7(1):e29929.

22. Riesco-Eizaguirre G, Wert-Lamas L, Perales-Paton J, SastrePerona A, Fernandez LP, Santisteban P. The miR-146b-3p/PAX8/ NIS regulatory circuit modulates the differentiation pPhenotype and function of thyroid cells during carcinogenesis. Cancer Res. 2015;75(19):4119-30.

23. Griesing S, Kajino T, Tai MC, Liu Z, Nakatochi M, ShimadaY, et al. Thyroid transcription factor-1-regulated microRNA-532-5p targets KRAS and MKL2 oncogenes and induces apoptosis in lung adenocarcinoma cells. Cancer Sci. 2017;108(7):1394-404.

24. Lakshmanan A, Wojcicka A, Kotlarek M, Zhang X, Jazdzewski $\mathrm{K}$, Jhiang SM. microRNA-339-5p modulates Na+/l- symportermediated radioiodide uptake. Endocr Relat Cancer. 2015;22(1):11-21.

25. Shen CT, Qiu ZL, Song HJ, Wei WJ, Luo OY. miRNA-106a directly targeting RARB associates with the expression of $\mathrm{Na}(+) / /(-)$ symporter in thyroid cancer by regulating MAPK signaling pathway. J Exp Clin Cancer Res. 2016;35(1):101.

26. Czajka AA, Wojcicka A, Kubiak A, Kotlarek M, Bakula-Zalewska E, Koperski $L$, et al. Family of microRNA-146 Regulates RARbeta in Papillary Thyroid Carcinoma. PLoS One. 2016;11(3):e0151968.

27. Yip L, Kelly L, Shuai Y, Armstrong MJ, Nikiforov YE, Carty SE, et al. MicroRNA signature distinguishes the degree of aggressiveness of papillary thyroid carcinoma. Ann Surg Oncol. 2011;18(7):2035-41.

28. David CJ, Massague J. Contextual determinants of TGFbeta action in development, immunity and cancer. Nat Rev Mol Cell Biol. 2018;19(7):419-35.

29. D'Inzeo S, Nicolussi A, Ricci A, Mancini P, Porcellini A, Nardi F, et al. Role of reduced expression of SMAD4 in papillary thyroid carcinoma. J Mol Endocrinol. 2010;45(4):229-44.

30. Matsuo SE, Fiore AP, Siguematu SM, Ebina KN, Friguglietti $\mathrm{CU}$, Ferro MC, et al. Expression of SMAD proteins, TGF-beta/ activin signaling mediators, in human thyroid tissues. Arq Bras Endocrinol Metabol. 2010;54(4):406-12.

31. Fuziwara CS, Kimura ET. High iodine blocks a Notch/miR-19 loop activated by the BRAF(V600E) oncoprotein and restores the response to TGFbeta in thyroid follicular cells. Thyroid. 2014;24(3):453-62.

32. Geraldo MV, Yamashita AS, Kimura ET. MicroRNA miR-146b-5p regulates signal transduction of TGF-beta by repressing SMAD4 in thyroid cancer. Oncogene. 2012;31(15):1910-22.

33. Matsuo SE, Leoni SG, Colquhoun A, Kimura ET. Transforming growth factor-beta1 and activin A generate antiproliferative signaling in thyroid cancer cells. J Endocrinol. 2006;190(1):141-50.

34. Pisarev MA, Thomasz L, Juvenal GJ. Role of transforming growth factor beta in the regulation of thyroid function and growth. Thyroid. 2009;19(8):881-92.

35. Nicolussi A, D'Inzeo S, Santulli M, Colletta G, Coppa A. TGF-beta control of rat thyroid follicular cells differentiation. Mol Cell Endocrinol. 2003;207(1-2):1-11.
36. Costamagna E, Garcia B, Santisteban P. The functional interaction between the paired domain transcription factor Pax8 and Smad3 is involved in transforming growth factor-beta repression of the sodium/iodide symporter gene. J Biol Chem. 2004;279(5):3439-46.

37. Kang HC, Ohmori M, Harii N, Endo T, Onaya T. Pax-8 is essential for regulation of the thyroglobulin gene by transforming growth factor-beta1. Endocrinology. 2001;142(1):267-75.

38. Riesco-Eizaguirre G, Rodriguez I, De la Vieja A, Costamagna E, Carrasco N, Nistal M, et al. The BRAFV600E oncogene induces transforming growth factor beta secretion leading to sodium iodide symporter repression and increased malignancy in thyroid cancer. Cancer Res. 2009;69(21):8317-25.

39. Qi J, Rice SJ, Salzberg AC, Runkle EA, Liao J, Zander DS, et al. MiR-365 regulates lung cancer and developmental gene thyroid transcription factor 1. Cell Cycle. 2012;11(1):177-86.

40. Eloy C, Santos J, Cameselle-Teijeiro J, Soares P, SobrinhoSimoes M. TGF-beta/Smad pathway and BRAF mutation play different roles in circumscribed and infiltrative papillary thyroid carcinoma. Virchows Arch. 2012;460(6):587-600.

41. Lamouille S, Xu J, Derynck R. Molecular mechanisms of epithelialmesenchymal transition. Nat Rev Mol Cell Biol. 2014;15(3):178-96.

42. Xu J, Acharya S, Sahin O, Zhang Q, Saito Y, Yao J, et al. 14-3-3zeta turns TGF-beta's function from tumor suppressor to metastasis promoter in breast cancer by contextual changes of Smad partners from p53 to Gli2. Cancer Cell. 2015;27(2):177-92.

43. Kalluri R, Weinberg RA. The basics of epithelial-mesenchymal transition. J Clin Invest. 2009;119(6):1420-8.

44. Xu J, Lamouille S, Derynck R. TGF-beta-induced epithelial to mesenchymal transition. Cell Res. 2009;19(2):156-72.

45. Anelli V, Villefranc JA, Chhangawala S, Martinez-McFaline R, Riva E, Nguyen A, et al. Oncogenic BRAF disrupts thyroid morphogenesis and function via twist expression. Elife. 2017;6. pii: e20728.

46. Knauf JA, Sartor MA, Medvedovic M, Lundsmith E, Ryder M, Salzano $M$, et al. Progression of BRAF-induced thyroid cancer is associated with epithelial-mesenchymal transition requiring concomitant MAP kinase and TGFbeta signaling. Oncogene. 2011;30(28):3153-62.

47. Puli OR, Danysh BP, McBeath E, Sinha DK, Hoang NM, Powell RT, et al. The transcription factor ETV5 mediates BRAFV600E-induced proliferation and TWIST1 expression in papillary thyroid cancer cells. Neoplasia. 2018;20(11):1121-34.

48. Lv N, Shan Z, GaoY, Guan H, Fan C, Wang H, et al. Twist1 regulates the epithelial-mesenchymal transition via the NF-kappaB pathway in papillary thyroid carcinoma. Endocrine. 2016;51(3):469-77.

49. Davis BN, Hilyard AC, Nguyen PH, Lagna G, Hata A. Smad proteins bind a conserved RNA sequence to promote microRNA maturation by Drosha. Mol Cell. 2010;39(3):373-84.

50. Gregory PA, Bert AG, Paterson EL, Barry SC, Tsykin A, Farshid $\mathrm{G}$, et al. The miR-200 family and miR-205 regulate epithelial to mesenchymal transition by targeting ZEB1 and SIP1. Nat Cell Biol. 2008;10(5):593-601.

51. Park SM, Gaur AB, Lengyel E, Peter ME. The miR-200 family determines the epithelial phenotype of cancer cells by targeting the E-cadherin repressors ZEB1 and ZEB2. Genes Dev. 2008;22(7):894-907.

52. Braun J, Hoang-Vu C, Dralle H, Huttelmaier S. Downregulation of microRNAs directs the EMT and invasive potential of anaplastic thyroid carcinomas. Oncogene. 2010;29(29):4237-44.

53. Zhang Z, Liu ZB, Ren WM, Ye XG, Zhang YY. The miR-200 family regulates the epithelial-mesenchymal transition induced by EGF/EGFR in anaplastic thyroid cancer cells. Int $\mathrm{J}$ Mol Med. 2012;30(4):856-62.

54. Vosgha H, Ariana A, Smith RA, Lam AK. miR-205 targets angiogenesis and EMT concurrently in anaplastic thyroid carcinoma. Endocr Relat Cancer. 2018;25(3):323-37. 
55. Ma S, Jia W, Ni S. miR-199a-5p inhibits the progression of papillary thyroid carcinoma by targeting SNAI1. Biochem Biophys Res Commun. 2018;497(1):181-6.

56. Wang Z, Zhang H, Zhang P, Dong W, He L. MicroRNA-663 suppresses cell invasion and migration by targeting transforming growth factor beta 1 in papillary thyroid carcinoma. Tumour Biol. 2016;37(6):7633-44.

57. Geraldo MV, Nakaya HI, Kimura ET. Down-regulation of $14 \mathrm{q} 32$ encoded miRNAs and tumor suppressor role for miR-654-3p in papillary thyroid cancer. Oncotarget. 2017;8(6):9597-607.

58. Zhang X, Liu L, Deng X, Li D, Cai H, MaY, et al. MicroRNA 483$3 p$ targets Pard3 to potentiate TGF-beta1-induced cell migration, invasion, and epithelial-mesenchymal transition in anaplastic thyroid cancer cells. Oncogene. 2018; 38(5):699-715.

59. Hardin H, Guo Z, Shan W, Montemayor-Garcia C, Asioli S, Yu $X M$, et al. The roles of the epithelial-mesenchymal transition marker PRRX1 and miR-146b-5p in papillary thyroid carcinoma progression. Am J Pathol. 2014;184(8):2342-54.

60. Deng X, Wu B, Xiao K, Kang J, Xie J, Zhang X, et al. MiR-146b$5 \mathrm{p}$ promotes metastasis and induces epithelial-mesenchymal transition in thyroid cancer by targeting ZNRF3. Cell Physiol Biochem. 2015;35(1):71-82.

61. Ocana $\mathrm{OH}$, Corcoles R, Fabra A, Moreno-Bueno G, Acloque H, Vega $S$, et al. Metastatic colonization requires the repression of the epithelial-mesenchymal transition inducer Prrx1. Cancer Cell. 2012;22(6):709-24.

62. Fu H, Cheng L, Jin Y, Cheng L, Liu M, Chen L. MAPK inhibitors enhance HDAC inhibitor-induced redifferentiation in papillary thyroid cancer cells harboring BRAF (V600E): an in vitro study. MolTher Oncolytics. 2019;12:235-45.

63. Akhurst RJ. Targeting TGF-beta signaling for therapeutic gain. Cold Spring Harb Perspect Biol. 2017;9(10) pii:a022301.

64. Bellomo C, Caja L, Moustakas A. Transforming growth factor beta as regulator of cancer stemness and metastasis. $\mathrm{Br} \mathrm{J}$ Cancer. 2016;115(7):761-9.

65. Li L, Lv B, Chen B, Guan M, SunY, Li H, et al. Inhibition of miR-146b expression increases radioiodine-sensitivity in poorly differential thyroid carcinoma via positively regulating NIS expression. Biochem Biophys Res Commun. 2015;462(4):314-21. 